\author{
S.E. Froschermaier ${ }^{\mathrm{a}}$ \\ D. Werner ${ }^{\mathrm{b}}$ \\ S. Leike \\ M. Schneider ${ }^{\mathrm{b}}$ \\ $J$. Waltenberger ${ }^{\mathrm{c}}$ \\ W.G. Daniel b \\ M.P. Wirth \\ Departments of \\ a Urology, and \\ b Medicine, Technical University Dresden, \\ and \\ c Department of Medicine, \\ University of Ulm, Germany
}

\section{Enhanced External Counterpulsation as a New Treatment Modality for Patients with Erectile Dysfunction}

\section{Key Words}

Erectile dysfunction

External counterpulsation

Impotence

\begin{abstract}
Enhanced external counterpulsation (EECP) is a noninvasive treatment modality which can increase arterial blood flow in peripheral and coronary arterial disease. Several studies have demonstrated an increase in the flow of the internal iliacal artery and in carotid and renal perfusion during EECP treatment. We investigated the effect of EECP in patients with erectile dysfunction (ED). Thirteen patients were treated with EECP for 20 days, $1 \mathrm{~h}$ per day. Patients reported a significant improvement of penile rigidity after completion of the EECP treatment and a significant improvement of penile peak systolic flow was measured by Doppler sonography. No adverse effects were observed. In conclusion, EECP seems to be an effective treatment modality in patients with ED.
\end{abstract}

\section{Introduction}

Enhanced external counterpulsation with sequential pneumatic cuff inflation was introduced in 1983 by Zheng et al. [1]. EECP causes increase of diastolic pressure that leads to increased coronary perfusion pressure and enhanced coronary blood flow. The ratio of mean diastolic to mean systolic pressure is increased as well, thereby modifying the pulse pressure distribution in the aorta and increasing mean arterial pressure [2]. The result is an increased peripheral blood flow. Since the introduction of this treatment, several studies have shown the benefit of EECP in patients with coronary heart disease [3] or inter-

\begin{tabular}{ll}
\hline KARGER & ( 1999 S. Karger AG, Basel \\
Fax +4161306 1234 & 0042-1138/98/0613-0168\$17.50/0 \\
$\begin{array}{l}\text { E-Mail karger@karger.ch } \\
\text { www.karger.com }\end{array}$ & $\begin{array}{l}\text { Accessible online at: } \\
\text { http://BioMedNet.com/karger }\end{array}$
\end{tabular}

nal ear disorders [4]. Fricchione et al. [5] reported 12 patients with coronary heart disease who showed a significant improvement in myocardial ischemia following EECP. 33\% of these patients also reported an improved erectile activity. In 1997, the Multicenter Study of Enhanced External Counterpulsation (MUST-EECP) showed a decrease of episodes of angina pectoris by $39 \%$ and of nitroglycerin use by $54 \%$ after EECP treatment [6]. It was also shown that EECP was able to increase renal perfusion by $20 \%$, coronary artery perfusion by $20-40 \%$ [7-9], and the urinary output by $60.3 \%$ in healthy volunteers during EECP treatment [10]. However, flow volume in the internal iliac artery is increased by $140 \%$ during 
EECP [11]. Offergeld et al. [4] could demonstrate a benefit of EECP treatment in patients with internal ear disorders.

The aim of this study was to investigate whether EECP treatment can improve symptoms in patients with erectile dysfunction.

\section{Materials and Methods}

Between October 1995 and December 1997, 20 patients with erectile dysfunction were enrolled in a clinical study to evaluate the EECP treatment. All patients underwent Doppler echocardiography and duplex scan in order to exclude aortic regurgitation, deep vein thrombosis and aortic aneurysm. Thus, 7 patients had to be excluded. The remaining 13 patients were between 43 and 68 years old (mean $57.85 \pm 6.32$ ). All 13 patients had a stable life style and a stable sexual relationship. Six patients were diabetics on oral antidiabetic drugs, 12 patients were cigarette smokers and 4 patients had a beginning peripheral artery disease. Clinical evaluation included sexual history and serum hormone levels ( $\mathrm{LH}, \mathrm{FSH}$, prolactin, testosterone and free testosterone). No patient had received hormonal or yohimbine therapy within 5 months before entering the study, and all patients had a normal hormonal status. The classification of the patients was performed as follows: $\mathrm{E} 0=$ no erection; $\mathrm{E} 1=$ poor erection, immediate loss; E2 = soft erection, but adequate for coitus; E3 = full erection.

Before treatment, patients had to answer a questionnaire. In all patients, intracavernous pharmacotests with rising doses (5-10-15$20 \mu \mathrm{g}$ ) of PGE were performed several times until full erection was achieved (final PGE dose). The quality of erection was observed after the application of $5 \mu \mathrm{g}$ PGE. Three and $5 \mathrm{~min}$ after application of the final PGE dose, a duplex sonography of the cavernous body arteries was performed and the values for resistance index (RI) and peak systolic blood flow (PS) were measured.

For the EECP treatment the counterpulsation system of Vasomedical Inc. (Westbury, USA) was used. EECP works by sequential diastolic inflation and deflation of three pairs of cuffs applied to the patients calves, lower thighs and upper thighs. Timing of the cuff compression is triggered by the electrocardiogram. During diastole the cuffs inflated up to $300 \mathrm{~mm} \mathrm{Hg}$ starting with the distal pair of cuffs. During onset of systole, the external pressure is rapidly released. Thus, by 'milking' the blood back to the heart EECP leads to an increased diastolic aortic pressure and increased flow in the internal iliac arteries. The administered EECP treatment regimen was $1 \mathrm{~h}$ daily for 5 days a week over 4 weeks.

Within 1 week after completion of the last EECP session, a reevaluation of the patients (determination of the quality of erection, duplex sonography after intracavernosal PGE application) was performed. One month after completion of the EECP treatment the patients were asked to answer the questionnaire for a second time.

In 4 patients a blood sample of the cavernous body was taken before and after the EECP treatment. After centrifugation serum was obtained and stored at $-175^{\circ} \mathrm{C}$ until assayed. The concentration of vascular endothelial growth factor (VEGF) was determined before and after EECP with the Quantikine ${ }^{\mathrm{TM}}$ human VEGF Immunoassay (R\&D Systems). VEGF is one of the marker proteins of induced angiogenesis.
Table 1. Quality of erection (E0-3), peak systolic flow (PS) and resistance index (RI) after pharmacological testing with PGE before and after EECP: for statistical differences the Wilcoxon test was performed

\begin{tabular}{llll}
\hline & $\begin{array}{l}\text { PS, cm/s } \\
(\text { mean } \pm \mathrm{SD})\end{array}$ & $\begin{array}{l}\text { RI } \\
(\text { mean } \pm \mathrm{SD})\end{array}$ & $\begin{array}{l}\text { Quality of erection } \\
(\text { mean } \pm \mathrm{SD})\end{array}$ \\
\hline Before EECP & $0.32 \pm 0.17$ & $0.58 \pm 0.06$ & $1.46 \pm 0.67$ \\
After EECP & $0.60 \pm 0.35$ & $0.67 \pm 0.07$ & $2.31 \pm 0.48$ \\
p value & 0.017 & 0.008 & 0.003 \\
\hline
\end{tabular}

Table 2. The ability of sexual intercourse (SI) before and after EECP

\begin{tabular}{lclcl}
\hline $\begin{array}{l}\text { Age } \\
\text { (years) }\end{array}$ & \multicolumn{2}{l}{ Possible SI in \% of all attempts } & $\begin{array}{l}\text { Follow-up } \\
\text { (months) }\end{array}$ & $\begin{array}{l}\text { Duration of } \\
\text { improvement } \\
\text { (months) }\end{array}$ \\
\cline { 2 - 4 } & before EECP & after EECP & 8 & 2 \\
60 & 0 & $>20$ & 24 & - \\
55 & 0 & 0 & 17 & 4 \\
54 & 0 & $>50$ & - & - \\
43 & 0 & $>20$ & 13 & 6 \\
57 & $<20$ & $>50$ & 9 & 9 \\
64 & 0 & satisfactory SI & 18 & 14 \\
50 & $<20$ & $>50$ & 25 & 12 \\
63 & $<20$ & satisfactory SI & 10 & 10 \\
57 & $<20$ & satisfactory SI & 6 & 6 \\
68 & $<20$ & $>50$ & 2 & - \\
59 & 0 & 0 & 2 & 2 \\
61 & 0 & satisfactory SI & 2 & 2 \\
61 & $<20$ & $>50$ & \\
\hline
\end{tabular}

\section{Results}

Before EECP treatment, 7 of the 13 patients were completely unable to have penetrative sexual intercourse (SI), 6 patients only in $<20 \%$ of all attempts. Ten of the 13 patients reported no spontaneous morning erections within the last year before EECP treatment.

One week after completion of the EECP treatment there was a significant improvement in peak systolic flow $(p=0.017)$, a significant change in the penile resistance index $(\mathrm{p}<0.008)$ and in the quality of erection $(\mathrm{p}<0.003)$ after application of $5 \mu \mathrm{g}$ PGE (table 1). Five of the 13 patients reported a considerable subjective improvement in penile rigidity so that satisfactory SI was now possible, 6 patients reported an improvement of penile rigidity and satisfactory SI more often than before treatment. In 2 patients penile rigidity remained unchanged (table 2 ). 


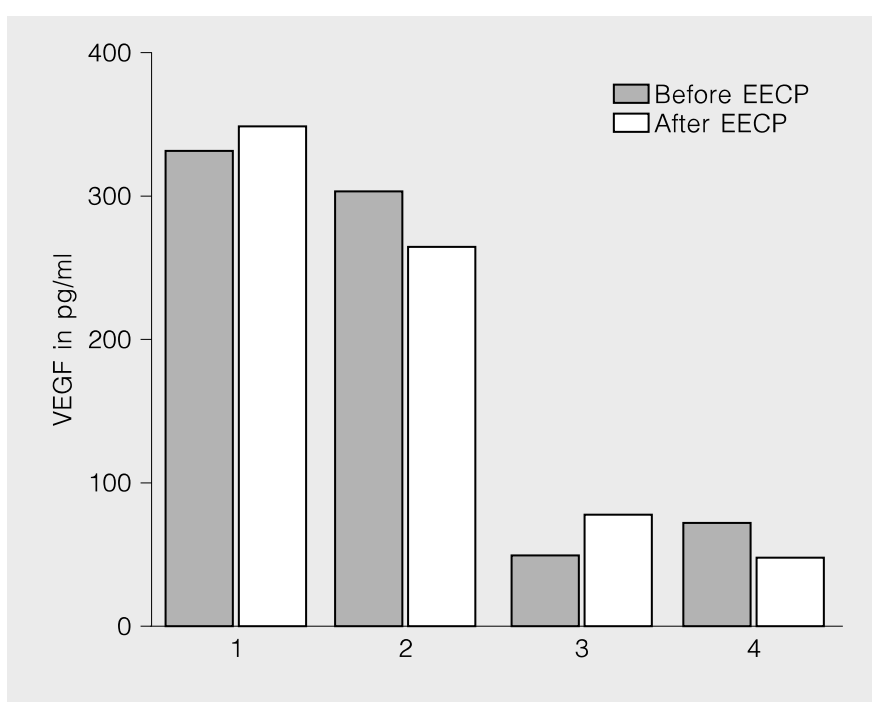

Fig. 1. Serum concentration of VEGF before and after 4 weeks EECP treatment in 4 patients.

Eight of 10 patients reported that spontaneous morning erections, previously absent, had returned after EECP. The mean follow-up time was $11 \pm 7.35$ months. Mean duration of response (in the 11 responders) was $6.7 \pm$ 4.37 months. No side effects of EECP treatment were reported. The determination of the VEGF concentrations before and after EECP treatment revealed no significant $(p=0.072)$ difference (fig. 1).

\section{Discussion}

Erectile dysfunction (ED) is a common health disorder in elderly men. About $67 \%$ of men aged 70 years have some degree of ED [12]. Although the interest in sexual activity often remains high in elderly men, less than $5 \%$ receive adequate treatment [12]. One reason for this is that until Sildenafil no satisfacotry noninvasive treatment was available. The main treatment alternatives are: (1) oral drug therapy; (2) vacuum constriction devices; (3) intracavernous or intraurethral vasoactive drug application; (4) penile prosthesis implantation, and (5) venous and arterial surgery [13]. Until recently, the mainstay of oral drug therapy was yohimbine, but the outcome data for this drug therapy do not indicate a significant effect [14]. Sildenafil, a new therapeutic agent for oral treatment [15] is a potent inhibitor of cyclic guanosine monophosphate in the corpus cavernosum and leads to an increased penile response to sexual stimulation. In an investigation by Goldstein et al. [16] 69\% of all attempts at sexual intercourse were successful in the Sildenafil group compared to $22 \%$ in the placebo group. The most common adverse effects were headache, flushing and dyspepsia.

The use of vacuum constriction devices and the penile application of vasoactive drugs is reliable, however both are not easy to use, and considerable side effects like prolonged erection are possible. In addition, both methods do not allow spontaneous sexual activity. In an investigation by Gerber and Levine [17], 51\% of the patients who entered a pharmacological erection program using PGE discontinued the program due to adverse effects like penile pain. The risks of penile prosthesis implantation are infection, erosion, mechanical failure and subsequent reoperation. The use of venous and arterial surgery is still investigated. Padma-Nathan et al. [18] investigated the effectiveness of intraurethral Alprostadil application and reported a response rate of $64.9 \%$ compared to $18.6 \%$ for placebo. The reported adverse effects were penile pain (32.7\%), minor urethral trauma $(5.1 \%)$ and dizziness (1.9\%). Kim and McVary [19] investigated the effects of topical PGE application to the penis. They showed a significant increase of mean peak systolic flow velocity and 2 of 9 patients had clinical erections after application.

EECP has been shown to improve peripheral blood flow and could therefore be assumed to improve erectile function in men with vascular ED as well. In our opinion, EECP offers a simple and noninvasive treatment for ED of predominantly vascular origin. Nine of 13 patients (69\%) reported a considerable improvement of the ability of sexual intercourse after EECP treatment and the mean duration of response after completion of EECP for these patients was 7.2 months. With proper patients selection, side effects have not to be expected. Furthermore, patients will benefit generally by improved peripheral vascular perfusion of other organs. The significant increase in peak systolic flow indicates also an improvement in penil perfusion resulting in an increased resistance index. The mechanism of the improvement in penile rigidity is unclear. One possible explanation is that the increased arterial perfusion during EECP treatment opens existing or leads to the development of new collateral channels. Increase of peak systolic flow after PGE could be a hint for improved vascular reagibility. However, the EECP treatment is time consuming and thus costly. The need for repetitive therapy has also to be taken into account. 


\section{Conclusion}

EECP is safe and has been shown to be an effective treatment modality in patients with ED. However, larger studies are needed to define subgroups of patients which benefit the most. EECP seems a promising treatment alternative especially for patients with generalized peripheral vascular disease and erectile dysfunction.

\section{Acknowledgment}

The VEGF measurements were done by Dipl. Biol. Andrea Kranz, Ulm.

\section{References}

1 Zheng ZS, Li TM, Kambic H, Chen GH, Yu LQ, Cai SR, Zhan CY, Chen YC, Wo SX, Chen GW: Sequential external counterpulsation (SECP) in China. Trans Am Soc Artif Intern Organs 1983;29:599-603.

2 Wonka F, Werner D, Krinke HE, Funk R, Daniel WG: Nichtinvasive Blutdruckmessung unter den Bedingungen einer externen Gegenpulsation. Biomed Tech 1997;42(suppl):472473.

3 Lawson WE, Hui JC, Soroff HS, Zheng ZS, Kayden DS, Sasvary D, Atkins H, Cohn PF: Efficacy of enhanced external counterpulsation in the treatment of angina pectoris. Am J Cardiol 1992;70:859-862.

4 Offergeld C, Werner D, Schneider M, Hüttenbrink KB: Sequential external counterpulsation: A potential new treatment for therapy resistant internal ear disorders? Eur Arch OtoRhino-Laryngol 1997;48(suppl):254.

5 Fricchione GL, Jaghab K, Lawson W. Hui JCK, Jandorf L, Zheng ZS, Cohn PF, Soroff H: Psychosocial effects of enhanced external counterpulsation in the angina patient. Psychosomatics 1995;36:494-497.

6 Arora RR, Jain D, Nesto RW, Fleishman B, Crawford L, McKiernan T: Results of the Multicenter Study of Enhanced External Counterpulsation (MUST-EECP): EECP reduces anginal episodes and exercise-induced myocardial ischemia. Circulation 1997;95(suppl 1):466.
7 Applebaum RM, Kaslival R, Tunik PA, Konecky N, Katz ES, Trehan N, Kronzon I: Sequential external counterpulsation increases cerebral and renal blood flow. Am Heart J 1997;133:611-615.

8 Nonnast-Daniel B, Werner D, Schneider M, Gross P, Daniel WG: Sequential external counterpulsation: A new noninvasive method to increase renal artery flow and perfusion. Nephrol Dial Transplant 1996;11(suppl 1):86.

9 Schneider M, Werner D, Nonnast-Daniel B, Garlichs C, Schwarz T, Schellong S, Daniel WG: Duplex sonographic findings during pneumatic external counterpulsation. Circulation 1996;94(suppl 1):608.

10 John A, Tragner P, Werner D, Zhang H, Daniel WG, Gross P: Sequential external counterpulsation (SECP) improves renal perfusion and excretion in healthy volunteers. Nephrol Dial Transplant 1997;12(suppl 1):55.

11 Werner D, Hui JCK, Kropp J, Daniel WG: Pneumatische externe Gegenpulsation: Therapieoption bei Angina pectoris. Z Kardiol 1998; 87(suppl 2):in press.

12 Godschalk MF, Sison A, Mulligan T: Management of erectile dysfunction by the geriatrician. J Am Geriatr Soc 1997;45:1240-1246.
13 Montague DK, Barada JH, Belker AM, Levine LA, Nadig PW, Roehrborn CG, Sharlip ID, Bennett AH: Clinical guidelines panel on erectil dysfunction: Summary report on the treatment of organic erectile dysfunction. J Urol 1996;156:2007-2011.

14 Teloken C, Rhoden EL, Sogari P, Dambros M, Souto CA: Therapeutic effects of high dose yohimbine hydrochloride on organic erectile dysfunction. J Urol 1998;159:122-124.

15 Boolell M, Gepi-Attee S, Gingell JC, Allen MJ: Sildenafil, a novel effective oral therapy for male erectile dysfunction. Br J Urol 1996;78: 257-261.

16 Goldstein I, Lue TF, Padma-Nathan H, Rosen RC, Steers WD, Wicker PA: Oral sildenafil in the treatment of erectile dysfunction: Sildenafil Study Group. N Engl J Med 1998;338:13971404.

17 Gerber GS, Levine LA: Pharmacological erection program using prostaglandin $\mathrm{E}_{1}$. J Urol 1991;146:786-789.

18 Padma-Nathan H, Hellstrom WJ, Kaiser FE, Labasky RF, Lue TF, Nolten WE, Norwood PC, Peterson CA, Shabsigh R, Tam PY: Treatment of men with erectile dysfunction with transurethral alprostadil. N Engl J Med 1997; 336:1-7.

19 Kim ED, McVary KT: Topical prostaglandinE1 for the treatment of erectile dysfunction. J Urol 1995; 153:1828-1830. 